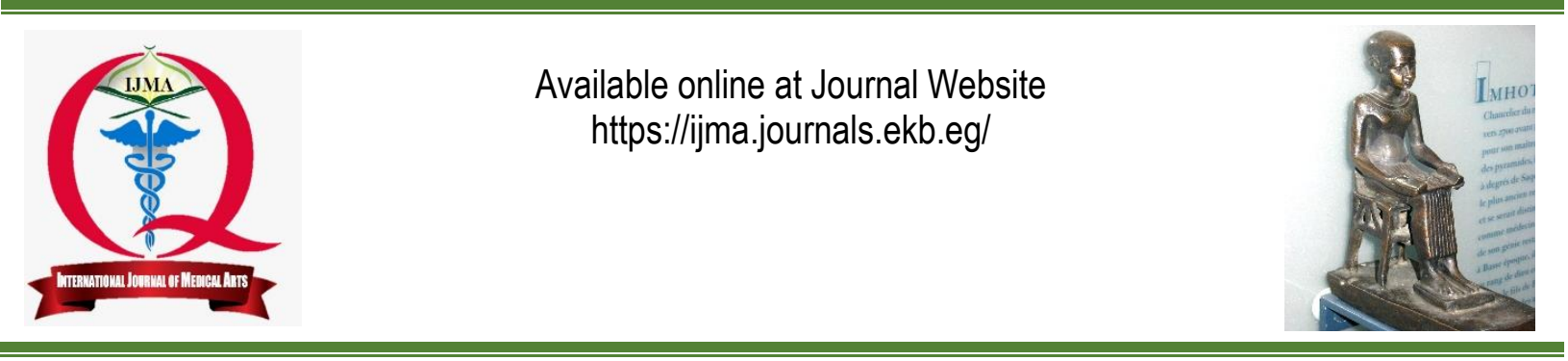

Original article

\title{
The Effect of Phototherapy on Serum Level of Tumor Necrosis Factor Alpha in Neonates
}

\author{
Mohamed Ali Naemª; Mohamed Abdelsalam Zannoun;
}

Department of Pediatrics, Damanhour General Hospital, Ministry of Health, Egypt[a].

Department of Pediatrics, Damietta Faculty of Medicine, Al-Azhar University, Egypt $[\mathrm{b}]$.

Corresponding author: Mohamed Ali Naem

Email: Roka.sose2012@gmail.com

Received at: May 9, 2019; Revised at: September 13, 2019; Accepted at: October 29, 2019; Available online at: October 29, 2019

\section{ABSTRACT}

Background: Jaundice is one of the most common conditions confronting neonatologists daily. Phototherapy is generally regarded as a safe method for treating hyperbilirubinemia, but it may also lead to undesired effects, one of these effects that it can affect the function of the immune system of the newborn.

Aim of the work: The aim of the work was to study the effect of phototherapy on the serum level of tumor necrosis factor- alpha [TNF-a] in neonates.

Patients and methods: A total of 35 cases of term neonates with Neonatal Jaundice and indirect hyperbilirubinemia high to the level that need phototherapy for $72 \mathrm{hrs}$ or more according to the guidelines of the American Academy of Pediatrics were included in this study, and 15 healthy matched newborns were selected as controls. TNF-a was measured before exposure and after 72 hours phototherapy and from control group at the time of examination. Serum levels of TNF alpha were measured using enzyme linked immunosorbent assay kits.

Results: The results showed that there was no statistically significant in patient group before phototherapy in comparison to control group as regards TNF-a, patient demographics or laboratory data. On the other side, serum TNF-a levels significantly increased after exposure to phototherapy for 72 hours when compared to values before phototherapy $(151.49 \pm 61.97$ vs $61.36 \pm 31.96$ respectively), indicating the influence of phototherapy on serum level of TNF-a.

Conclusion: The results demonstrated increased serum TNF-a level after 72 hours may affect the immune system in neonates.

Keywords: Phototherapy; Jaundice; Immune system; Cytokines; Neonate.

This is an open access article under the Creative Commons license [CC BY] [https://creativecommons.org/licenses/by/2.0/]

Please cite this article as: Naem MA, Zannoun MA. The Effect of Phototherapy on Serum Level of Tumor Necrosis Factor Alpha in Neonates. IJMA 2020; 2[1]: 157-161. 


\section{INTRODUCTION}

Neonatal jaundice is the yellowish discoloration of the sclera and skin caused by hyperbilirubinemia and it is one of the most common conditions confronting neonatologists daily. About $60 \%$ of term and $80 \%$ of preterm infants develop jaundice in the first week of life[1].

Bilirubin is pigmented which causes a yellowing of the baby's skin and tissues. A low level of bilirubin is usually not a concern as most infants will experience a certain amount of physiological jaundice which results in no problems. However, if unconjugated bilirubin levels rise rapidly above a safe level and are left untreated the bilirubin can cross the blood-brain barrier and be deposited in the brain stem (basal ganglia) and cerebellum, disrupting cellular metabolism causing irreversible brain damage (bilirubin encephalopathy) leading to kernicterus. Bilirubin encephalopathy occur first and later kernicterus [2].

Phototherapy has been effectively used as a relatively inexpensive and noninvasive method of treating neonatal hyperbilirubinemia[3].

Phototherapy is generally regarded as a safe method for treating hyperbilirubinemia, but it may also lead to undesired effects including skin rashes, diarrhea, body temperature rise, chills, trauma to the eye, nasal obstruction, bronze baby and DNA damage. Phototherapy may be associated with some long term side effects such as melanocytic nevi and skin cancer, allergic diseases, PDA and retinal damage. Recently, phototherapy is one of the potent risk factors of childhood asthma, allergic rhinitis and conjunctivitis[4].

During the last few decades, some investigation have expressed concern about potential toxic effects of phototherapy on cytokines production and lymphocyte subtypes, which can affect the function of the immune system of the newborn ${ }^{[5]}$.

Cytokines are hormones-like proteins that enable immune cells to communicate, initiate, perpetuate and subsequent down regulate of the immune response[6].

TNF-a is considered a proinflammatory cytokine involved in the innate immune response ${ }^{[7]}$.

It is one of the most important cytokines secreted in patients with infection or in those exposed to acute UV radiation; it is a glycoprotein hormone with important functions in inflammation and apoptosis. It plays a significant role as a pro inflammatory cytokine in the defense mechanism against infections and autoimmune disorders ${ }^{[8]}$.

\section{AIM OF THE WORK}

The aim of the work was to study the effect of phototherapy on the serum level of TNF-a in neonates.

\section{PATIENTS AND METHODS}

This study was carried out in Pediatric Department, Damietta Faculty of Medicine, AlAzhar University. This case control study was conducted on 50 full-term neonates of both sexes, their gestational age 37 weeks and more. They were classified into: Group 1(cases): 35 term neonates with neonatal jaundice and indirect hyperbilirubinemia high to the level that need phototherapy for 72 hours or more according to the guidelines of the American Academy of Pediatrics (AAP), TNF- $a$ was measured before and after phototherapy. Group 2 (control): 15 of healthy term neonates.

Inclusion criteria: Full-term neonates with neonatal hyperbilirubinemia in whom the use of phototherapy had begun according to the guidelines of the AAP (cases), both sexes, any mode of delivery and gestational age 37 weeks or more.

Exclusion criteria: Congenital malformations, congenital infections associated with the TORCH complex, respiratory distress, hypoxia, exchange transfusion, direct bilirubin levels higher than 2 $\mathrm{mg} / \mathrm{dl}$, newborn of mothers with pre-eclampsia, steroid treatment or diabetes mellitus, neonatal sepsis and preterm neonates.

Each neonate in this study was subjected to the following: Full history taking with special emphasis on perinatal history (maternal age, antenatal care), maternal medical disorders during pregnancy especially diabetes mellitus, hypertension, manifestations suggestive of intra uterine infections, preeclampsia, vaginal bleeding and/or premature rupture of membranes [PROM]. In addition, natal history was obtained and included: date of delivery, mode of delivery, multiple gestations, presentation at delivery, and obstructed 
labor or asphyxia. The family history included consanguinity and similar conditions in other siblings.

Full clinical examination was carried out and stressed on examination of general condition, central nervous system (CNS), cardiovascular system (CVS), respiratory system, abdomen and genitalia. Also, anthropometric measure (birth weight, length and head circumference at birth) and plotted on growth charts of World Health Organization (WHO) Growth Charts 2009.

Laboratory investigations included complete blood count (CBC), C-reactive protein (CRP), bilirubin (total and direct) and tumor necrosis factora.

Two samples were taken at each time: one sample complete blood count; the other sample for $\mathrm{CRP}$, total and direct serum bilirubin and TNF-a. Samples from controls were collected at the time of examination.

\section{RESULTS}

The demographic data of the studied group showed that the studied neonates were $46 \%$ females and $54 \%$ males with a mean age 3.59 days

Both patients and control groups were comparable regarding mode of delivery and birth order. In addition, no significant difference was found regarding neonatal weight, height or head circumference (Tables 1 and 2).

Table (3) Revealed that, mean CRP values in patients group was $1.37 \pm 1.59$, while in control group, it was $0.53 \pm 0.92$ with no significant difference between groups. In addition, TNF-a before therapy was $61.36 \pm 31.96$ in patient group and $45.67 \pm 6.93$ in control group with no statistically significant difference. On the other side, TNF-a after phototherapy in patients group was significantly increased when compared to pre-phototherapy values $\quad(151.49 \pm 61.97$ vs $61.36 \pm 31.96$ respectively).

Table (1): Comparison between patient group \& control group as regards mode of delivery (MOD), birth order

\begin{tabular}{|c|l|c|c|c|c|c|c|}
\hline \multicolumn{2}{|c|}{} & \multicolumn{2}{|c|}{ Patient group } & \multicolumn{2}{c|}{ Control group } & \multicolumn{2}{c|}{ Chi square test } \\
\cline { 3 - 8 } \multicolumn{2}{|c|}{} & No. & $\%$ & No. & $\%$ & $\mathbf{X}^{2}$ & p value \\
\hline \multirow{3}{*}{ Mode of delivery } & CS & 27 & $77.1 \%$ & 11 & $73.3 \%$ & \multirow{2}{*}{0.084} & 0.773 \\
\cline { 2 - 7 } & NVD & 8 & $22.9 \%$ & 4 & $26.7 \%$ & & \\
\hline \multirow{3}{*}{ Order birth } & First & 11 & $31.4 \%$ & 3 & $20.0 \%$ & & \multirow{3}{*}{0.637} \\
\cline { 2 - 7 } & Second & 13 & $37.1 \%$ & 8 & $53.3 \%$ & & \\
\cline { 2 - 6 } & Third & 6 & $17.1 \%$ & 3 & $20.0 \%$ & & \\
\cline { 2 - 6 } & Fourth & 5 & $14.3 \%$ & 1 & $6.7 \%$ & & \\
\hline
\end{tabular}

Table (2): Comparison between patient group \& control group as regards anthropometric measure of babies

\begin{tabular}{|l|c|c|c|c|c|c|}
\hline \multirow{2}{*}{} & \multicolumn{2}{|c|}{ Patient group } & \multicolumn{2}{c|}{ Control group } & \multicolumn{2}{c|}{ Independent t test } \\
\cline { 2 - 7 } & Mean & SD & Mean & SD & $\mathbf{t}$ & p value \\
\hline Weight $(\mathrm{kg})$ & 3.08 & 0.25 & 3.11 & 0.21 & 0.491 & 0.626 \\
\hline HC & 34.53 & 0.51 & 34.53 & 0.44 & 0.031 & 0.975 \\
\hline Height $(\mathrm{cm})$ & 49.61 & 0.57 & 49.47 & 0.44 & 0.893 & 0.376 \\
\hline
\end{tabular}

(3): Comparison between patient group \& control group as regards CRP

\begin{tabular}{|l|c|c|c|c|c|c|}
\hline & \multicolumn{2}{|c|}{ Patient group } & \multicolumn{2}{c|}{ Control group } & \multicolumn{2}{c|}{ Independent t test } \\
\cline { 2 - 7 } & Mean & SD & Mean & SD & $t$ & p value \\
\hline CRP & 1.37 & 1.59 & 0.53 & 0.92 & 1.902 & 0.063 \\
\hline TNF-a before $(\mathrm{pg} / \mathrm{ml})$ & 61.36 & 31.96 & 45.67 & 6.93 & 1.872 & 0.067 \\
\hline TNF- $\alpha$ after $(\mathrm{pg} / \mathrm{ml})$ & 151.49 & 61.97 & - & - & - & - \\
\hline Paired comparison & \multicolumn{2}{|c|}{ Paired (t): $\mathbf{8 . 6 5 1 ,} \boldsymbol{p}<\mathbf{0 . 0 0 1 ^ { * }}$} & & & & \\
\hline
\end{tabular}




\section{DISCUSSION}

Jaundice is a common condition in newborn infants and is a clinical sign of excess conjugated or unconjugated bilirubin (hyperbilirubinemia). It is characterized by a yellow coloring of the infant's skin and other tissues caused by high levels of circulating unconjugated bilirubin due to the breakdown of red blood cells. Jaundice is present when serum bilirubin is $>85$ micromoles/l. There is a $60 \%$ incidence of jaundice in full term infants (1st week) and $80 \%$ incidence in preterm infants ${ }^{[9]}$.

Phototherapy is the most commonly used intervention to treat and prevent severe hyperbilirubinemia [10].

Exposure to UV radiation initiates a complex cascade of responses resulting in the downregulation of the immune system. Various immune mediators such as IL- 1, IL-6, IL-10 and TNF-alpha are secreted by the immune system of skin to support the systemic immunologic response [11].

NNPT inhibits the immune system, ultimately causing allergic diseases during childhood and later in life. NNPT can significantly increase the levels of TNF- $\alpha, I L-1 \beta$ and IL-8, in newborn infants. UV light in NNPT significantly decreases circulating CD4+ T lymphocyte counts, interferes with CD8+ cytotoxic $T$ lymphocytes and reduces natural killer cell activity. Therefore, it affects the immune system and leads to allergy and autoimmunity disorders ${ }^{[4]}$.

TNFa is a cell signaling protein (cytokine) involved in systemic inflammation and is one of the cytokines that make up the acute phase reaction[12].

The relationship between Phototherapy and increasing in TNF-alpha level and other cytokines level was a subject of debate. This study explores the relationship between the effect of phototherapy on serum level of TNF-alpha in neonates. Many other studies were done to explore the relationship between phototherapy and TNF-alpha level.

The present study revealed that comparison between patient group before treatment with phototherapy and control group regarding TNFalpha level showed no statistically significant difference. These results suggest that neonatal hyperbilirubinemia doesn't influence the serum levels of TNF-a. These results are in agreement with that of Kurt et al.[5] who stated that neonatal hyperbilirubinemia may have no effect on TNF-a level.

The present study revealed that there was statistically significant increase in TNF-a after phototherapy in comparison to before phototherapy in patient group. Serum TNF-a level significantly increased after 72 hours of exposure to phototherapy and this change was statistically significant $(P<0.001)$, indicating the strong effect of phototherapy on TNF-a serum level. These results are in agreement with that of Jahan et al.[13] who stated that exposure to phototherapy in the treatment of neonates with hyperbilirubinemia can affect the synthesis and release of cytokines from the peripheral immune system, as it increases serum TNF-a. In addition, these results are also in agreement with that of Maisels and McDonagh[14] who stated that an imbalance in the production of different cytokines induces immune system failure. UV radiation for treatment of neonatal hyperbilirubinemia induces an increase in IL-6, IL-8 and TNF-a. Moreover, this result is in agreement with that of Kurt et al. ${ }^{[5]}$ who stated that usage of phototherapy in neonate with jaundice as a treatment affects the function of the immune system in newborns through alterations in TNF-alpha production. Also, Narbutt et al.[11] stated that exposure of healthy term neonates to repeated doses of UV radiations shows a statistically significant increase in serum level of TNF- $\alpha$.

Moreover, our results are in agreement with that of Sirota et al.[15] who stated that phototherapy affects the function of the immune system in newborns by alterations in cytokine production. Exposure to UV radiation results in higher TNF-a production and suppression of many cell-mediated immune responses.

In contrast, our results are not in agreement with that of Procianoy et al.[16] who studied the influence of phototherapy on serum cytokine concentrations in newborn infants; there were no statistical differences in TNF- $\alpha$ concentrations before and after $24 \mathrm{~h}$ of phototherapy.

In summary, TNF-a significantly increased after phototherapy in full term neonates denoting that, it could affect the immune system in neonates. 


\section{REFERENCES}

1. Rennie J, Burman-Roy S, Murphy MS; Guideline Development Group. Neonatal jaundice: summary of NICE guidance. BMJ. 2010; 340:c2409. [DOI:10.1136/bmj.c2409].

2. American Academy of Pediatrics. Management of Hyperbilirubinaemia in the newborn infant 35 or more weeks of gestation. Pediatrics 2004; 114,297316. [DOI: 10.1542/peds.114.1.297].

3. Slusher TM, Olusanya BO, Vreman HJ, Brearley AM, Vaucher YE, Lund TC et al. A Randomized Trial of Phototherapy with Filtered Sunlight in African Neonates. N Engl J Med. 2015; 373 (12): 1115-24. [DOI: 10.1056/NEJMoa1501074].

4. Xiong $\mathrm{T}, \mathrm{Qu} \mathrm{Y}$, Cambier S, Mu D. The side effects of phototherapy for neonatal jaundice, what do we know? What should we do? Chinese J Contemp Pediatr 2011; 170 (10):1454-1462. [DOI: 10.1007/ s00431-011-1454-1].

5. Kurt A, Aygun AD, Kurt AN, Godekmerdan A, Akarsu S, Yilmaz E. Use of phototherapy for neonatal hyperbilirubinemia affects cytokine production and lymphocyte subsets. Neonatology 2009; 95:262266. [DOI: 10.1159/000171216].

6. Mclnnes IB, Furst DE, Romain PL. Role of cytokines in rheumatic diseases. Uptodate 2013:7997.

7. Clark IA. How TNF was recognized as a key mechanism of disease. Cytokine Growth Factor Rev. 2007; 18 (3-4): 335-43. [DOI:10.1016/j.cytogfr.2007.04.002].

8. Mrkaiae L, Kamenov B, Najman S, Dimitrijević H, Mitrović V, Maglajlić S. Neonatal immune system changes caused by phototherapy. Srp Arh Celok Lek 1994; 122:36-37. [PMID: 18173182].

9. Hellowell F, Crathern L. Hyperbilirubinemia in the newborn infant (part 2). A review of the background literature and critical review of the current research paper findings on the topic. $J$ Neonatal Nursing 2011; 17(4): 132-138. [DOI: 10.1016/j.jnn. 2010. 08. 004].
10. Cashore WJ. Bilirubin and jaundice in the micropremie. Clin Perinatol 2000; 27: 171-9. [DOI: 10.1016/ s0095-5108 (05)70012-9].

11. Narbutt J, Lesiak A, Skibinska M, Wozniacka A, SysaJedrzejowska A, Lukamowicz J, van Loveren $H$. Repeated does of UVR cause minor alteration in cytokine serum levels in humans. Mediators Inflamm 2005; 5:298-303. [DOI: 10.1155/MI.2005. 298].

12. Lin WW, Karin M. A cytokine-mediated link between innate immunity, inflammation, and cancer. J Clin Invest. 2007; 117(5): 1175-83. [DOI: 10.1172/ $\mathrm{JCl} 31537]$.

13. Jahan S, Ahmadpour-Kacho M, Pasha YZ. Effects of phototherapy on cytokines' levels and white blood cells in term neonate with hyperbilirubinemia. J Clin Neonatol 2012; 1:139-42. [DOI: 10.4103/22494847. 101696].

14. Maisel MJ, McDonagh AD. Phototherapy for Neonatal Jaundice. N Engl J Med. 2008; 358:920-928. [DOI: 10.1056/NEJMct0708376].

15. Sirota L, Straussberg R, Gurary N, Aloni D, Bessler H. Phototherapy for neonatal hyperbilirubinemia affects cytokine production by peripheral blood mononuclear cells. Eur J Pediatr 1999; 158:910 913. [DOI:10.1007/s004310051240].

16. Procianoy RS, Silveira RC, Fonseca LT, Heidemann LA, Neto EC. The influence of phototherapy on serum cytokine concentrations in newborn infants. Am J Perinatol 2010; 27:375- 379. [DOI:10.1055/s0029-1243311]. 